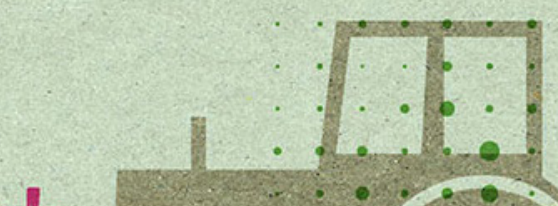

$+$
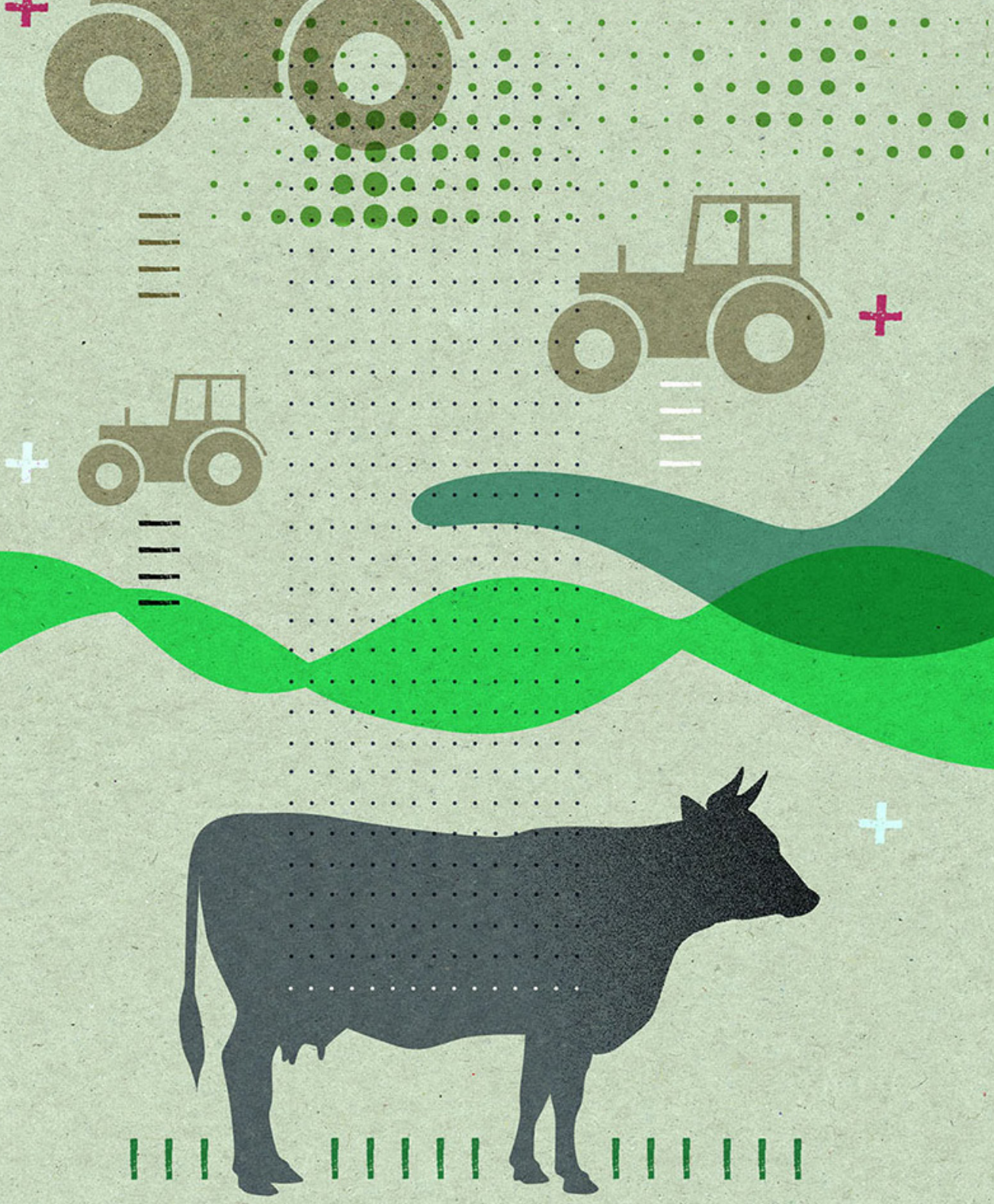


\section{A Embrapa e a formação de seus pesquisadores: objetivo, processo e perfil alcançado}

\section{Embrapa and researchers training: objective, process and achieved profile}

Alex A. Mengel*

\section{Resumo}

Este artigo considera a constituição da Embrapa como fator decisivo para a estruturação da pesquisa agropecuária nacional a partir da década de 1970, da mesma maneira, considera que a formação de seu quadro de pesquisadores é elemento fundamental para a explicação de sua trajetória institucional. Assim, este trabalho tem dois objetivos: 1) compreender o perfil do profissional eleito pela sua direção para compor o quadro de pesquisadores; 2) entender como foram constituídos os processos responsáveis pela formação deste quadro. A análise fundamenta-se no conceito de "ação social" e de "instituição" de Max Weber (2009), bem como no conceito de campo de Pierre Bourdieu (1997). Os dados aqui examinados foram obtidos por meio de pesquisa documental efetuada nas bibliotecas da empresa e pela aplicação de entrevistas semiestruturadas a 22 pesquisadores e lideranças que trabalham ou haviam trabalhado em 11 centros da empresa, além de pessoas que trabalhavam em departamentos e secretarias da Embrapa Sede.

Palavras-chave: pesquisa agropecuária, industrialização da agricultura, Embrapa.

\begin{abstract}
This article considers the constitution of Embrapa as a decisive factor for the structuring of the national agricultural research from the 1970s, in the same way, considers that the formation of its staff of researchers is a fundamental element for the explanation of its institutional trajectory. Thus, this work has two objectives: 1) to understand the profile of the professional chosen by its management to compose the research team; 2) understand how the processes responsible for the formation of this framework were constituted. The analysis is based on the concept of "social action" and "institution" of Max Weber (2009), as well as on the field concept of Pierre Bourdieu (1997). The data examined here were obtained through documentary research carried out in the company's libraries and through the application of semistructured interviews to 22 researchers and leaders who worked or worked in 11 centers of the company, as well as people who worked in departments and Secretariats of Embrapa Headquarters.
\end{abstract}

Keywords: Agricultural research, industrialization of agriculture, Embrapa.

\footnotetext{
* Doutor em Ciências Sociais, mestre em Ciências Sociais, graduado em EngenhariaAgronômica. Professor adjunto da Universidade Federal do Rio Grande do Sul/ Campus Litoral Norte/ Departamento Interdisciplinar, no Programa de Pós-Graduação em Dinâmicas Regionais e Desenvolvimento, no Bacharelado Interdisciplinar em Ciência e Tecnologia e no Bacharelado em Desenvolvimento Regional. https://orcid.org/0000-0002-5470-4922. E-mail: alex.mengel@ufrgs.br
} 


\section{INTRODUÇÃO}

De modo geral, tem-se em mente que o processo de construção do conhecimento é determinado por pesquisadores e, por conseguinte, que estes pesquisam aquilo que lhes é de interesse e que lhes parece importante para a resolução de questôes relevantes à sociedade. Entretanto, se o objetivo é entender, de maneira mais detalhada, como o processo de construção de conhecimento se efetiva, é preciso ultrapassar essa compreensão inicial. Assim, faz-se mister considerar o peso da instituição da qual estes cientistas fazem parte para a definição dos temas e problemas de pesquisa prioritários.

Com o ímpeto de compreender elementos definidores da construção do conhecimento científico agropecuário existente atualmente, estudou-se o processo que gerou a criação da Embrapa e sua posterior consolidação. A Embrapa é uma empresa criada a partir do grupo de trabalho, instituído em 1972 pelo Ministro da Agricultura Cirne Lima, encarregado de analisar o então Sistema de Pesquisa Agropecuário Brasileiro. A escolha por esta empresa, construída pelo governo militar, ocorre por esta ter se tornado central na estruturação da pesquisa agropecuária nacional. Atualmente é a instituição com mais recursos, mais pesquisadores e mais pesquisas nessa área ${ }^{1}$. Este artigo considera a constituição desta empresa como fator decisivo para a construção da pesquisa agropecuária nacional a partir da década de 1970.

O presente trabalho tem dois objetivos: o primeiro é compreender o perfil do profissional eleito pela sua direção para compor o quadro profissional de pesquisadores; o segundo é entender como foram constituídos os processos responsáveis pela formação deste quadro de pesquisadores.

Para subsidiar essa análise fundamenta-se no conceito de "ação social" de Weber $(2009)^{2}$. Entende-se a pesquisa científica como uma ação social, ou seja, uma atividade humana qualquer, onde quem a desempenha leva em consideração o comportamento de outrem, sendo esta ação também influenciada por interesses dos pesquisadores, costumes, convençóes sociais e legislação de uma sociedade.

Tratar a pesquisa científica desta maneira possibilita compreender, por um lado, que a direção tomada na construção do conhecimento não é a única possível, e sim aquela que melhor atende aos interesses daqueles responsáveis por sua construção. Por outro lado, permite considerar o conhecimento como algo completamente dependente da realidade, costumes e convençốes presentes na sociedade. Além do conceito de ação social, na presente análise torna-se fundamental o conceito de instituição, também elaborado por Weber (2009) ${ }^{3}$. De acordo com este conceito as ações desenvolvidas por uma instituição têm relação direta com os interesses de seus criadores e dirigentes, 
e tais interesses marcam sua ordem. Assim, a construção do conhecimento depende, além da sociedade onde é construído, dos interesses e da ordem da instituição de onde o mesmo provém.

Para compreender de maneira mais acurada como os interesses tem papel fundamental na definição da atividade científica, opta-se pela utilização do conceito de "campo" de Pierre Bourdieu (1997). Tal conceito auxilia na reflexão sobre a maneira como os atores responsáveis pela administração da instituição conseguem influenciar a direção do conhecimento por ela formado.

Este trabalho fundamenta-se na análise de dados colhidos por meio de pesquisa documental efetuada nas bibliotecas da empresa, e em informaçóes obtidas através da aplicação de entrevistas semiestruturadas a 22 pesquisadores e lideranças que trabalham ou haviam trabalhado em 11 centros da empresa, além de pessoas que trabalhavam em departamentos e secretarias da Embrapa Sede.

\section{EMBRAPA: INTERESSES DOMINANTES NA AGRICULTURA E PESQUISA AGROPECUÁRIA}

A razão pela qual a Embrapa foi criada é evidenciada no texto denominado "As unidades de difusão de tecnologia da EMBRAPA", datado de 1975, escrito por Eliseu Roberto de Andrade Alves, um dos fundadores e então Diretor da empresa. A questão, em idos de 1970, para a direção da empresa nascente, era a aproximação entre o setor industrial e agrícola.

Quando se fala em "packages tecnológicos” para o desenvolvimento da agricultura é importante que se considere um outro tipo de interação, ou seja, a simbiose entre a pesquisa agrícola com a industrial. Por exemplo, a industrialização de alimentos constitui hoje em dia uma fonte de problemas e respostas para a pesquisa agronômica: o desenvolvimento da indústria de fertilizantes e implementos proporciona respostas e problemas para a pesquisa agronômica. Na verdade, a história das sociedades que se desenvolveram nas últimas décadas ensina que o crescimento da produção e produtividade agrícola só foi alcançado quando o setor industrial proporcionou respostas adequadas em termos de inovaçóes mecânicas e biológicas (ALVES, 1972, p. 28).

No período histórico da criação da Embrapa, eram necessárias pesquisas que solucionassem problemas para uma completa integração entre agricultura e indústria. Essa modificação na maneira de realizar pesquisas se traduz nos pacotes tecnológicos. O objetivo central da empresa, no momento de sua criação, era pensar em sistemas de produção que tivessem incluídos agricultores, fabricantes de maquinários, insumos e beneficiadores de produtos agrícolas. A antiga instituição, o Departamento Nacional de Pesquisa e 
Experimentação Agropecuária $\left(\mathrm{DNPEA}^{4}\right)$ já produzia conhecimentos muito relevantes, traduzidos em tecnologias, como mostram os resultados relatados por Rodrigues (1987) ou Mendonça (2012), entretanto, eram conhecimentos voltados à agricultura como setor autossuficiente e não voltados à agricultura como parte de um complexo agroindustrial. Como ressalta Alves (1975), eram conhecimentos gerados sob outros princípios. O surgimento da EMBRAPA é parte da construção do entrelaçamento entre setores industriais e agrícola, processo que hoje é considerado quase como uma evolução natural para uma agricultura moderna, mas que foi bastante complexo e não teria ocorrido sem a transformação da pesquisa brasileira.

\section{A SELEÇÃO DO QUADRO DE PESQUISADORES}

De acordo com Schrader e Cabral (1972), no ano de 1972 existiam 851 pesquisadores agrícolas no quadro do DNPEA, 927 no quadro dos governos estaduais, além de 142 que eram funcionários de outras organizaçóes, totalizando assim 1.920 pesquisadores que atuavam na pesquisa agropecuária em todo o país. Além disso, pertenciam ao quadro do $\mathrm{MEC}^{5} 2.000$ profissionais responsáveis pelo ensino agrícola técnico e superior, além de 405 profissionais no quadro dos governos estaduais, totalizando 2.405 profissionais responsáveis pelo ensino agrícola técnico e superior em nível nacional.

Os dados apresentados por Schrader \& Cabral (1972) evidenciam que o número de profissionais voltados para a pesquisa viria a ser fortemente impactado com a criação da Embrapa, pois a empresa passou a contar, em dez anos, com mais de 1600 pesquisadores, o que significa uma duplicação no número de pesquisadores agropecuários federais, considerados os números do início da década de 1970.

Schrader \& Cabral (1972), ainda demonstram que dos 851 técnicos do DNPEA, 677 eram graduados, 93 eram mestres ou doutores e 81 estavam estudando. Sendo assim, aproximadamente $80 \%$ dos pesquisadores do DNPEA eram somente graduados, e $10,9 \%$ eram mestres ou doutores (SCHRADER \& CABRAL, 1972). A partir dos dados do DRH da Embrapa, expostos por Souza e Trigueiro (1985), percebe-se que o perfil de pesquisadores agropecuários do quadro federal se modificou rapidamente após a criação da empresa, pois, após dez anos, $17 \%$ dos pesquisadores eram graduados, $62 \%$ eram mestres e $22 \%$ eras doutores.

Com a Tabela 01, evidencia-se que e a Embrapa, a partir de sua criação contrata graduados, mestres e doutores. No ano de sua fundação é composta somente por doutores, aqueles que compunham sua direção, em seu segundo ano, $83 \%$ de seu quadro é composta por graduados. O primeiro 
aumento substancial do número de mestres e doutores acontece entre 1977 e 1978, ano em que o número de graduados que faziam parte de seu quadro cai pela metade. Tal dado evidencia os primeiros resultados do programa de pós-graduação da empresa. A partir deste momento o número de mestres e doutores que fazem parte da companhia crescem progressivamente.

Tabela 1 - Pesquisadores da Embrapa, por nível de qualificação e por ano.

\begin{tabular}{l|r|r|r|r}
\hline \multirow{2}{*}{ Ano } & \multicolumn{3}{|c|}{ Pesquisadores } & \multirow{2}{*}{ Total } \\
\cline { 2 - 4 } & Graduação & MSc & PhD & \\
\hline 1973 & - & - & 12 & 12 \\
\hline 1974 & 724 & 133 & 15 & 872 \\
\hline 1975 & 832 & 178 & 27 & 1037 \\
\hline 1976 & 1098 & 194 & 36 & 1328 \\
\hline 1977 & 1086 & 188 & 37 & 1311 \\
\hline 1978 & 543 & 702 & 91 & 1336 \\
\hline 1979 & 548 & 777 & 123 & 1448 \\
\hline 1980 & 509 & 882 & 162 & 1553 \\
\hline 1981 & 439 & 941 & 196 & 1576 \\
\hline 1982 & 403 & 968 & 226 & 1597 \\
\hline 1983 & 355 & 986 & 269 & 1610 \\
\hline 1984 & 320 & 1001 & 298 & 1619 \\
\hline 1985 & 275 & 1012 & 363 & 1650 \\
\hline
\end{tabular}

Fonte: Adaptada de (SOUZA \& TRIGUEIRO, 1989)

Tal constatação evidencia que todos os profissionais contratados para serem pesquisadores, ou quase a totalidade, eram enviados diretamente para fazer pós-graduação. Isso sugere também que não existiam profissionais com mestrado ou doutorado disponíveis quando a Embrapa foi criada, pois é somente quatro anos depois do início de suas atividades que acontece o primeiro aumento substancial no número de mestres. $\mathrm{O}$ mesmo raciocínio se aplica aos doutores. Tais elementos são outra evidência da sensível modificação no campo da pesquisa agropecuária brasileira, gerada pela criação da Embrapa.

O programa de pós graduação da Embrapa e sua importância na formação do quadro da empresa

Quando eu cheguei aqui, toda a EMBRAPA, em junho de 75, todos os centros do Brasil, tinha 28 técnicos com PhD, 28. Já em 88, quando assim foi medido, tinha mais que 1000. Período de 12 anos foram treinados mais de 1000 pesqui- 
sadores em nível de doutorado, a maioria fora do Brasil e tinha bastante também, não sei quantos, uns 300 ou 400, formados com mestrado, estes a maioria foram formados no Brasil (LevonYeganiantz ${ }^{6}$, agosto de 2013).

Os fundamentos daquilo que se configurou no programa de pós-graduação da Embrapa é evidenciado no trecho do documento "Informaçôes sobre o projeto de pós-graduação (Versão Preliminar)”, de 1975.

O Programa de Formação de Recursos Humanos da Embrapa fundamenta-se nos seguintes pontos:

(1) Preparar os pesquisadores para que as metas e objetivos da Embrapa sejam cumpridos. Quer isto significar que o ponto de partida são as metas e objetivos da Embrapa;

(2) Ser dimensionado de tal forma a:

$\left({ }^{*}\right)$ Ajudar a remover, no curto prazo, o déficit constatado de pesquisadores. Neste caso, não só as necessidades da Embrapa como de outras instituiçốes ligadas à pesquisa agrícola devem ser consideradas.

$\left(^{*}\right)$ Facilitar o ajustamento da oferta às variações do perfil e do crescimento da demanda por pesquisadores.

$\left(^{*}\right)$ Preparar pesquisadores em quantidade e qualidade que satisfaçam às necessidades da Embrapa e do Sistema que se integrar a ela.

(5)Enfatizar a formação de liderança e de administradores de pesquisa. Sem líderes e administradores competentes, a execução de tarefas de pesquisa fica extremamente difícil, ou é mesmo impossível;

(6) Reconhecer que a Universidade é a base fundamental de todo treinamento e que necessita ser estimulada e adaptada;

(8) Reconhecer que a par dos conhecimentos especializados, é importante dar ao pesquisador uma visão global do modelo brasileiro de desenvolvimento para que saiba selecionar seus projetos de pesquisa dentro do contexto deste modelo. No que respeita aos pesquisadores do quadro da Embrapa ou do Sistema que ela vier a formar, além da visão acima, é importante criar no pesquisador a mística da organização e do Sistema, de modo que compreenda os seus propósitos e objetivos, sua filosofia e maneira de encarar os problemas da agricultura e, desta forma, sentindo-se parte integrante, colabore decisiva e entusiasticamente na tarefa que é de todos. 
(10) Ter como princípio fundamental de treinamento, o estímulo à criatividade. Reconhecer que a tarefa mais nobre e mais difícil do pesquisador é a formulação de problemas relevantes e que um treinamento forte em metodologia e teoria ajuda neste aspecto, na proporção que é heterodoxo e desafiador e, que prejudica, quando é dogmático, ritualista, tradicional, repetitivo e excessivamente baseado em textos e aulas formais (EMBRAPA, 1975, s/p).

Ao analisar-se os fundamentos do programa de pós-graduação percebe-se que ele foi pensado como ferramenta central da construção de uma instituição que visava tornar-se um thinktank $k^{7} \mathrm{da}$ industrialização da agricultura brasileira. Divide-se tais fundamentos da seguinte maneira: (1) Alcançar os objetivos e metas definidos pela direção da empresa, tarefa central a ser perseguida pelo programa, de modo que o oferecimento de vagas às demais organizaçôes faziam parte deste objetivo; (2) formar lideranças e administradores de pesquisa, tendo em vista os objetivos da empresa; (3) preocupava-se com o fortalecimento e com a modificação das universidades brasileiras; (4) buscava fazer com que seus pesquisadores compartilhassem da visão global do modelo brasileiro de desenvolvimento comum à direção da empresa e aos grupos aos quais ela fazia parte da época; (5) preocupava-se em criar nos pesquisadores uma "mistica da organização de pesquisa" (EMBRAPA, 1975, $\mathrm{s} / \mathrm{p}$ ), em outras palavras, em instituir as regras formais e informais da instituição; ou então, procurava criar, em seu quadro, os valores comuns que fundamentariam ordem vigente da empresa; (6) uma forte formação em teoria e metodologia científica.

Era central o fortalecimento da instituição, e a partir deste objetivo derivavam os demais, tais como a necessidade de modificação do perfil profissional das demais organizações que trabalhavam com pesquisa agropecuária, e a necessidade de formar líderes e administradores.

\section{Seleção do quadro: um olhar a partir dos profissionais contratados}

A seleção do quadro de profissionais da Embrapa é compreendida a partir das discussóes a respeito da necessidade de modernização da agricultura brasileira, de mudança na instituição de pesquisa agropecuária brasileira, e da necessidade de modificação de perfil do pesquisador agropecuário. Considerando tais questóes, entrevistou-se vários pesquisadores contratados pela Embrapa na década de 1970 ou no início da década de 1980, como mencionado na introdução deste trabalho. Aqui, com vistas a compreender a maneira como aconteceu o processo de seleção da empresa, utiliza-se os relatos de Alberto Miele, Elisio Contini, Elsio Figueiredo, José Carlos Souza 
Silva e Murilo Flores. O primeiro profissional já era pesquisador do IPEAS ${ }^{8}$, pertencente ao DNPEA; já os quatro últimos são profissionais contratados, na época, recém-formados.

Alberto Miele, em entrevista concedida em junho de 2013, relata suas impressões a respeito de como aconteceu o processo de seleção daqueles profissionais que compunham o DNPEA. O interlocutor explica que os profissionais poderiam optar em permanecer no quadro do Ministério da Agricultura ou ingressar na nova empresa, sendo que aqueles que optassem deveriam passar por uma seleção.

Com a criação da Embrapa, então, eu já estava aqui [Estação Experimental de Bento Gonçalves], eu e mais 3, os outros três da enologia. Só eu e o chefe daquela época, o Saraiva, optamos por ficar na Embrapa. A seleção, eu lembro que eu estava aí e a Embrapa precisa mandar o pessoal, como eu te falei, novos conhecimentos com o mestrado e doutorado, eu fui fazer mestrado (...). Então o que eu sei daqui, dos quatro, eu me prontifiquei, eu me interessei em ir e os outros não optaram por ir, tanto é que dois quiseram ficar no Ministério da Agricultura, o outro estava na chefia, de certo, eu não sei bem, deve ter preferido ficar na chefia. (Alberto Miele', junho de 2013).

No relato de Miele é presente que um pré-requisito importante para ser selecionado pela comissão era a aceitação do ingresso no programa de pósgraduação da empresa. Sobre a escolha da área de estudo e da universidade na qual deveria realizar seu mestrado, Alberto Miele faz o seguinte relato:

Eu fui, então, pra Universidade da Califórnia, onde eu fiz o mestrado, em fisiologia vegetal, porque aqui já tinha pessoal de enologia e a Embrapa disse " $n \tilde{a} o$, tu tem que ir nessa área de fisiologia vegetal que nós estamos precisando", então eu fui fazer fisiologia vegetal na Universidade da Califórnia em Davis. Na época eu era engenheiro agrônomo e a Embrapa disse "Ilha, nósprecisamos de fisiologia vegetal, Davis é um dos melhores centros do mundo em fisiologia vegetal, a Universidade da Califórnia”, então eles me mandaram imediatamente pra lá (Alberto Miele, junho de 2013).

Com o exposto por Miele, é evidente que tanto a área na qual o profissional iria se especializar, por meio de sua pós-graduação, quanto a universidade a ser escolhida para a especialização eram decisóes tomadas pela empresa. Elsio Figueiredo relata como acontecia o processo seletivo na época, as dificuldades de comunicação e o número reduzido de profissionais disponíveis na sociedade, o que, certamente, influenciava na maneira como ocorria o recrutamento e a seleção do quadro.

Era análise de currículo. Acho que tinha notícia. A comunicação naquela época em 74, 75, não existia internet, não existia notícia, não existia jornal, entende. Não tinha como tu encontrar uma chamada, não era assim como é hoje que 
você abre o jornal e tá lá. Talvez até tivesse no jornal, alguma coisa, mas eu não me lembro. Era mais o professor da universidade que te orientava. Ia se formar e falava com o professor, "onde nós podemos encontra um lugar para trabalbar?" ele dizia "olha tem ai a EMATER, tem instituto de pesquisa, tem a EMBRAPA, a Universidade". Aí você escrevia para eles para saber. Era assim, pelo que eu me lembro, você tinha que tomar a iniciativa. Então tinha alguma coisa assim. Isso durou um período longo, foi um período de contratação de quatro anos, mais ou menos, cinco anos. (Elsio Figueiredo ${ }^{10}$, junho de 2013).

Percebe-se os problemas que os agentes responsáveis por selecionar o quadro da Embrapa encontravam. Uma comunicação restrita e um número de profissionais limitado, com certeza, são fatores que dificultam a seleção.

É claro, no depoimento de Elsio Figueiredo, que foi fundamental em sua seleção ter aceitado continuar sua formação por meio do programa de pósgraduação. É evidente também, que já em sua seleção lhe foi determinada a área de estudos e a universidade na qual ele deveria realizar seu mestrado.

Figueiredo: Bem, a EMBRAPA me convidou para trabalhar se eu aceitasse fazer o mestrado em Viçosa, na área de Melhoramento Genético Animal. Então eu aceitei e fui fazer o mestrado em melhoramento genético animal, trabalhei com bovino de corte e depois de terminada a tese ela me locou na EMBRAPA Caprinos.

Mengel: Então a seleção da EMBRAPA estava condicionada à pós-graduação?

Figueiredo: A currículo primeiro e depois, ela estava montando o quadro, então ela estava procurando gente para as áreas que tinha necessidade. Abria vaga, olhava os currículos e indicava se esse currículo aceitava fazer mestrado em tal área, em tal universidade. E a contratação só saia quando você estava tudo certo, matriculado no curso e tudo.

Mengel: Então a exigência era a formação?

Figueiredo: É, eu só fui contratado quando já estava matriculado no curso (Elsio Figueiredo, junho de 2013).

José Carlos Souza Silva também apresenta um relato sobre como foi selecionado para a empresa. Para o interlocutor, um fator essencial no processo de formação do quadro de pesquisadores da Embrapa era o número insuficiente de profissionais na sociedade.

Na época a gente era convidado, não tinha nem seleção, porque não tinha profissionais no mercado, 1977. Então, Brasília tinha o que? Dezesseis anos, por aí, dezessete, era uma escassez muito grande de mão de obra qualificada. Então a gente era convidado. Não era só aqui, mesmo, em várias instituiçôes do país a coisa era mais fácil, entre aspas né, porque havia demanda e o número de profissionais era razoavelmente pequeno (José Carlos Souza Silva ${ }^{11}$, agosto de 2013). 
Dirceu Talamini descreve o processo de seleção ao qual foi submetido, conforme o trecho a seguir:

Bom, o fato é o seguinte, quando nós concluímos a Agronomia, no último ano, nos últimos meses nós recebemos a visita lá em Santa Maria de uma equipe da EMBRAPA que estava buscando identificar interessados em trabalhar na EMBRAPA. Aí nós nos inscrevemos e aí baseado no desempenho acadêmico, a informação que nós temos é que os 10 melhores colocados em cada turma foram convidados a trabalhar na EMBRAPA. Então nós fizemos os testes psicológicos, as entrevistas, e então formamos em dezembro de 73 e em março de 74 estávamos iniciando os trabalhos na EMBRAPA. Inicialmente em Sete Lagoas, no hoje Centro Nacional de Milho e Sorgo e naquela ocasião nós éramos desafiados a aderir aos programas de pós-graduação. Então nós entramos na EMBRAPA com graduação e nos inscrevemos na pós-graduação. E naquela ocasião já poderíamos ter ido diretamente aos Estados Unidos, uma turma muito grande foi apreender inglês nos Estados Unidos, em seguida fazer o mestrado (Dirceu Talamini ${ }^{12}$, junho de 2013).

Um elemento relevante em depoimento do interlocutor é a descrição do processo seletivo, que fortalece a ideia de que, neste período inicial de existência, havia várias formas de seleção.

Murilo Flores, como um dos contratados no período pós-criação da Embrapa, mas também como um importante dirigente da empresa que foi, explana sobre o processo de arregimentação do quadro de pesquisadores. Desta maneira, o interlocutor situa historicamente sua contratação como parte do processo ocorrido nos primeiros anos da empresa.

Eu sou das últimas contratações de um grupo de técnicos, das últimas contratações que a Embrapa fez no modelo que ela fez no início do anos 70. A Embrapa foi criada em 73 e eu fui contratado em 81. Era a fase final das contrataçóes daquele modelo. Que modelo era esse? Aí eu vou chegar também na minha formação. Não existia no Brasil pessoas no mercado, procurando emprego, com mestrado e doutorado, com experiência como pesquisador. Não existia naqueles anos. A oferta de mão de obra disponível, com formação de pós graduação, era muito pequena. E muito menos na área agrícola. Então a Embrapa tinha absorvido alguns grupos que vieram do Ministério da Agricultura e saiu procurando nas universidades gente que queria virar pesquisador. A pessoa recém-formada já era orientada a fazer uma pós graduação e isso aconteceu comigo. Eu fui da última leva desse perfil de pessoas que eram recém formados, normalmente em Agronomia, que era o meu caso, que faziam pós-graduação em áreas diferentes, áreas mais técnicas, mas também em áreas de humanas, que também foi o meu caso. Então eu fui fazer o mestrado em Economia Rural, eu era formado na Universidade de Brasília, em Agronomia, fiz um estágio, no período da minha conclusão do meu curso de Agronomia na Embrapa. Aí a Embrapa me ofereceu e condicionou a eu ser contratado, mas que eu fosse estudar, fazer mestrado. 
Hoje que todo mundo quer fazer, na época obrigava a fazer. Buscavam, na primeira leva era escancarado, eu já não fui tão assim, porque eu também estagiava na EMBRAPA. Mas nos primeiros anos era assim, você ia lá, pegava os bons alunos que tinham perfil para ser pesquisador. Porque ser pesquisador não basta querer, você tem que ter um perfil de pesquisador. Então se identificava esses perfis e tal e se levava para a EMBRAPA. E assim formou um grupo grande de pesquisadores com um perfil muito semelhante. (...) Pessoas com potencial de serem pesquisadores, pessoas que se dispunham a ir estudar nas universidades indicadas pela Embrapa, nas áreas que ela indicava, dentro desse modelo alinhado em torno da questão dos Centros de Produto, melhoramento genético e assim por diante (Murilo Flores, junho de 2013).

É possível perceber vários elementos relacionados ao processo seletivo da Embrapa, no depoimento de Murilo Flores. O primeiro é que a seleção acontecia por meio de contato com universidades, ou como o seu caso, devido a uma proximidade com a empresa, por meio de convite. Segundo, a maneira como ocorria a seleção é justificada pelo baixo número de profissionais existentes na sociedade, no período de formação da empresa. Terceiro, um requisito básico para ser aceito na empresa era estar disposto a realizar a pósgraduação onde a Embrapa viesse a indicar.

A respeito da área a realizar pós-graduação, bem como, da universidade escolhida, Murilo Flores discorre da seguinte maneira:

Eu propus que fosse na área de humanas, ou Sociologia ou Economia. Ela não se interessou que eu fizesse Sociologia e me direcionou para área de Economia e também me direcionou para a Universidade de Viçosa. Não foi escolha minha, fazer Economia em Viçosa, foi determinação da Embrapa. A Embrapa tinha um perfil que ela queria de pessoas, um perfil de pesquisadores, portanto, ela sabia quais eram as universidades que formavam pessoas para aquele perfil, e Viçosa era uma delas, que copiava muito o modelo de visão de agricultura americana, dos Estados Unidos (Murilo Flores, junho de 2013).

Mais uma vez é presente que a decisão sobre a instituição na qual poderia ser realizada a pós-graduação, nos anos iniciais da empresa, era uma prerrogativa da instituição e não do indivíduo, devendo ele aceitar para poder ser contratado. A partir dos depoimentos dos pesquisadores contratados nos anos iniciais após a criação da Embrapa pode-seconstatar: 1) aceitar participar do programa de pós-graduação era o requisito básico para ser contratado, sendo que o programa de pós-graduação era o elemento central para a compreensão da formação do quadro de pesquisadores da empresa; 2) eram os profissionais designados pela empresa para coordenar tanto a seleção quanto o programa de pós-graduação que definiam as instituiçóes para as quais os recém-contratados seriam enviados, e somente em casos específicos era facultada a escolha ao indivíduo contratado; 3) o profissional poderia ser contra- 
tado se ele já tivesse, de alguma maneira, proximidade com a empresa, por exemplo, se tivesse feito estágio na Embrapa. Poderia ele próprio entrar em contato com a empresa e solicitar participar da seleção. Ou então, a empresa iria às universidades para buscar selecionar alguns estudantes formandos. Em resumo, os dirigentes da empresa tinham grande flexibilidade para contratação, o que lhes dava um grande poder de agência ${ }^{13}$.

Seleção do Quadro: o programa de pós-graduação

De acordo com o documento "Informaçóes sobre o Projeto de Pós-Graduação (Versão Preliminar)”, datado de 1975, o sistema de seleção adotado pela empresa era dividido em sete etapas, da definição das necessidades da empresa à incorporação dos técnicos à instituição formadora.

1. Estimativa das necessidades atuais e potenciais de pesquisadores, por áreas de conhecimentos.

2. Levantamento da oferta de vagas nos centros de pós-graduação.

3. Recrutamento dos candidatos.

- Quadros da Empresa

- Quadros do Sistema Nacional de Pesquisa Agropecuária

- Recrutamento no mercado de trabalho

- Recrutamento nas Universidades

4. Pré-Seleção dos candidatos: (Feita por técnicos dos Departamentos da Empresa, por professores universitários e, em alguns casos, por técnicos do ACORDO.)

- Exame do "Curriculum Vitae"

* Qualificações

* Trabalhos de Pesquisa

* Potencial e preparo para pós graduação

* Idade

* Coerência na área de treinamento solicitada

* Estudos e pesquisas realizadas, etc.

- Exame do Histórico Escolar

${ }^{*}$ Desempenho acadêmico

* Posição na turma

- Resultados das indicações dos diretores e grupos de seleção das unidades da empresa ou do Sistema Nacional de Pesquisa.

- Entrevistas individuais

- Consideraçốes sobre hierarquia das prioridades. 
5. Indicação aos centros de pós graduação.

6. Seleção por parte dos centros de pós graduação.

7. Incorporação - dos selecionados - ao Programa de treinamento (EMBRAPA, 1975, s/p).

A seleção se iniciava, então, a partir de seu planejamento ${ }^{14}$, com a mensuração das necessidades de pesquisadores - e é importante dizer que se mensuravam as "necessidades atuais e potenciais", ou seja, a curto, médio e longo prazos. Antes do recrutamento dos candidatos, ainda se determinava onde estes seriam alocados. Como visto no depoimento dos pesquisadores, analisados anteriormente, não eram eles que escolhiam ou buscavam um centro de pós-graduação, pois tal escolha era prerrogativa do Departamento de Recursos Humanos.

claro que nós éramos uma instituição que tinha as suas prioridades, então mandamos gente de acordo com isso. (...) Nós distribuímos os nossos pesquisadores de acordo com as necessidades da EMBRAPA, mas sempre dentro do princípio de criar homens independentes e bom cientistas. Depois cada um, eles escolheram as universidades, a razão era a seguinte, olha, você pode ir para essas universidades. Quais eram as universidades? Aqui no Brasil tudo "Classe A" e no exterior também, as boas universidades de lá. Essa foi a regra. (Eliseu Alves, julho de 2013)

Considerando a perspectiva de Bourdieu (1997), a respeito do funcionamento de um campo, constata-se que, quando uma instituição atinge seus objetivos, está fortalecendo a posição de seus criadores, bem como de seus dirigentes, no campo em que atuam. Assim, tendo em vista a amplitude deste programa, é significativa a capacidade de influência que estes indivíduos tiveram sobre o campo da pesquisa agropecuária e, mais ainda, sobre as disputas pelos rumos da agricultura brasileira.

Ademais, o controle da formação do quadro profissional da instituição significa a criação de um corpo que compartilha determinados valores e conhecimentos que constituiriam a ordem vigente da empresa, no sentido weberiano, ou as regras formais e informais da empresa, que, por sua vez, integram parte do conhecimento tácito característico de uma instituição. Diferentemente do que diz o interlocutor, observa-se com os depoimentos dos pesquisadores selecionados, que a eles não era permitido escolher a universidade em que se qualificariam.

A respeito da escolha dos centros de pós-graduação adequados para a formação do quadro profissional da empresa, Fernando Campos, um dos funcionários do Departamento de Recursos Humanos responsável pela seleção, enumera três elementos fundamentais. $\mathrm{O}$ primeiro diz respeito aos 
financiadores do programa; o segundo diz respeito aos interesses da direção para a constituição de seu quadro de pesquisadores; e o terceiro refere-se à proximidade dos dirigentes da Embrapa daqueles centros onde os profissionais viriam a ser formados.

Olha, foram principalmente acordos com bancos internacionais. O Banco Interamericano para o Desenvolvimento e o Banco Mundial que financiaram a EMBRAPA. E aí vai uma ressalva; esses bancos, logicamente, o Banco Interamericano, eles tinham o interesse. Era muito capital americano. Então a principal fonte, vamos dizer, de uso desses recursos, seriam o próprio Estados Unidos. Então, esse direcionamento é muito para os Estados Unidos. E o tipo de formação do aluno nos Estados Unidos interessava muito a EMBRAPA, porque eram jovens muito novos e que, vamos dizer, formação como na França, Inglaterra ou Austrália, que tem um tipo diferente, uma formação acadêmica diferente, onde o aluno é que praticamente tem que ter a responsabilidade de fazer o seu currículo, muito aberto. Isso foi percebido pela direção da EMBRAPA, que poderíamos ter problema. Nós precisávamos ter um sistema onde que o aluno fosse muito monitorado, ele não tinha ainda maturidade, certo, para esse tipo de coisa. E deu certo. E deu certo por dois motivos, primeiro porque, vamos dizer, a relação com essas universidades foi tratada com muita proximidade. Das relaçôes de pessoas que já tinham estado lá, de dirigentes ou outras pessoas da EMBRAPA, o caso do Dr. Eliseu Alves que foi o grande mentor dessa formação massiva de pessoas na EMBRAPA, então. E o outro grande mérito foram que os alunos corresponderam, então a Universidade tinha prazer em ter alunos da EMBRAPA, porque eles correspondiam. Então isso ajudou muito. (Fernando Campos ${ }^{15}$, julho de 2013)

Como observado, a seleção do pessoal para compor o quadro da empresa confundia-se com a seleção para o programa de pós-graduação, pois só eram efetivados na empresa aqueles que se dispusessem a especializar-se na área em que a empresa necessitasse. Desta maneira, infere-se que a pré-seleção de que fala o documento de 1975 é o "convite” a que se referem os pesquisadores contratados naquela época, em seus relatos. Pode-se perceber que esta préseleção podia mesmo ser feita por técnicos das unidades da Embrapa ou por professores das universidades. Desta maneira, se um pesquisador da empresa tivesse, por exemplo, algum estagiário com bom desempenho, ele poderia ser contratado. Da mesma maneira, se algum professor, com relação com a empresa, tivesse um orientando promissor, poderia sugerir que a Embrapa o contratasse. Ainda chama atenção que estivesse previsto que os técnicos do Acordo MA/USAID ${ }^{16}$ também pudessem sugerir a contratação de candidatos para o programa.

Por último, destaca-se o depoimento de Eliseu Alves, Diretor do Departamento de Recursos Humanos da época. Seria difícil este pesquisador, 
realmente, ter controle sobre todo o processo, devido à magnitude do programa, mas chama-se a atenção para a capacidade de agência da equipe de selecionadores, dirigida por ele, visto que foram estes sujeitos os responsáveis pela contratação e formação de cerca de 1500 profissionais, em uma década.

Eu vou te falar como eu selecionei o pessoal. Isso ai foi eu que fiz, eu peguei, mandei selecionar os $5 \%$ dos melhores estudantes da Universidade e depois eu tinha um informante que me informava o caráter deles. Essa foi a única regra que teve. (Eliseu Alves, julho de 2013).

\section{NÚMEROS DO PROGRAMA: OBJETIVOS DA EMPRESA, FINANCIAMENTO, EQUIPE SELECIONADORA}

Por meio do documento "Programa de pós-graduação da Embrapa até o mês de dezembro de 1979" evidencia-se quais organizaçóes financiavam a formação de mestres e doutores para a Embrapa, no período indicado. Compilou-se, nas Tabelas 2 e 3, alguns dados existentes no documento supracitado, de modo a facilitar a visualização dos mesmos.

Tabela 2 - Quantitativo dos treinamentos de técnicos no país, por fonte financiadora, nível e ano de incorporação, até dezembro de 1979.

\begin{tabular}{l|c|c|c|c|c|c|c|c}
\hline \multirow{2}{*}{ Fonte Financiadora } & Nível & 1974 & 1975 & 1976 & 1977 & 1978 & 1979 & Total \\
\hline \multirow{2}{*}{ FIRD } & MSC & 258 & 151 & 226 & 007 & --- & --- & 642 \\
\cline { 2 - 9 } & PhD & 012 & 010 & 005 & 002 & --- & --- & 029 \\
\hline \multirow{2}{*}{ BID } & MSC & --- & --- & 005 & 039 & 056 & 041 & 141 \\
\cline { 2 - 9 } & PhD & --- & --- & --- & 002 & 002 & 008 & 012 \\
\hline \multirow{2}{*}{ CNPq } & MSC & --- & --- & --- & 007 & 019 & 012 & 038 \\
\cline { 2 - 9 } & PhD & --- & --- & --- & --- & --- & 008 & 008 \\
\hline \multirow{2}{*}{ CAPES } & MSC & 008 & 002 & --- & --- & --- & --- & 010 \\
\cline { 2 - 9 } & PhD & 002 & --- & --- & --- & --- & --- & 002 \\
\hline \multirow{2}{*}{ EMBRAPA } & MSC & 002 & --- & --- & --- & --- & --- & 002 \\
\cline { 2 - 9 } & PhD & --- & --- & --- & --- & --- & --- & --- \\
\hline \multirow{2}{*}{ Total } & MSC & 002 & --- & --- & --- & --- & 001 & 003 \\
\cline { 2 - 9 } & PhD & --- & --- & --- & --- & --- & --- & --- \\
\hline
\end{tabular}

Fonte: Documento interno do Departamento de Recursos Humanos da Embrapa (1979) 
Tabela 3 - Quantitativo dos treinamentos de técnicos no exterior, por fonte financiadora, nível e ano de incorporação, até dezembro de 1979

\begin{tabular}{|c|c|c|c|c|c|c|c|c|}
\hline Fonte Financiadora & Nível & 1974 & 1975 & 1976 & 1977 & 1978 & 1979 & Total \\
\hline \multirow[t]{2}{*}{ FINEP } & MSc & --- & --- & 002 & --- & 023 & --- & 025 \\
\hline & $\mathrm{PhD}$ & --- & --- & --- & --- & 038 & 001 & 039 \\
\hline \multirow[t]{2}{*}{ BIRD } & MSc & --- & --- & 016 & 012 & 013 & 012 & 053 \\
\hline & $\mathrm{PhD}$ & --- & --- & 008 & 013 & 026 & 023 & 070 \\
\hline \multirow[t]{2}{*}{ BID } & MSc & --- & --- & --- & 006 & 005 & 006 & 017 \\
\hline & $\mathrm{PhD}$ & --- & --- & --- & 002 & 006 & 006 & 014 \\
\hline \multirow[t]{2}{*}{ USAID } & MSc & 018 & 061 & 009 & --- & --- & --- & 088 \\
\hline & $\mathrm{PhD}$ & 009 & 002 & 004 & -- & --- & --- & 015 \\
\hline \multirow[t]{2}{*}{ CNPq } & MSc & --- & --- & --- & -- & --- & --- & --- \\
\hline & $\mathrm{PhD}$ & --- & 002 & --- & --- & --- & --- & 002 \\
\hline \multirow[t]{2}{*}{ G. ESTR. } & MSc & --- & --- & 003 & --- & --- & 001 & 004 \\
\hline & $\mathrm{PhD}$ & 001 & 001 & 001 & -- & 001 & --- & 004 \\
\hline \multirow[t]{2}{*}{ OUTRAS } & MSc & 010 & 009 & --- & 001 & --- & --- & 020 \\
\hline & $\mathrm{PhD}$ & --- & -- & --- & --- & --- & 001 & 001 \\
\hline \multicolumn{2}{|l|}{ Total } & 038 & 075 & 043 & 034 & 112 & 050 & 352 \\
\hline
\end{tabular}

Fonte: Documento interno do Departamento de Recursos Humanos da Embrapa (1979)

Com a Tabela 2, pode-se constatar que os maiores financiadores da parte do programa de pós-graduação da Embrapa, realizado nas universidades brasileiras entre 1974 e 1979, eram a FINEP o BIRD e o BID. A FINEP foi responsável por financiar $68,6 \%$ da formação de mestres e $54,23 \%$ de doutores. O BIRD financiou a formação de $16,3 \%$ dos mestres e $22 \%$ de doutores. Já o BID financiou $13,21 \%$ da formação de mestres e $18,64 \%$ de doutores. As três organizações financiaram, juntas, $98,11 \%$ da formação de mestres em universidades brasileiras, e 94,87\% de doutores. Já a Tabela 3 apresenta informações sobre os órgãos responsáveis por custear a formação de mestres e doutores no exterior. Com ela nota-se que os grandes financiadores do programa de pós-graduação da Embrapa, entre os anos de 1974 e 1979, foram a FINEP, o BIRD, o BID e a USAID. A FINEP financiou $17,6 \%$ da formação de mestres e $32,7 \%$ de doutores. O BIRD financiou $19,8 \%$ de mestres e $32,3 \%$ de doutores. O BID financiou $18,8 \%$ da formação de mestres e $21,4 \%$ de doutores. A USAID financiou a formação de $35,5 \%$ de mestres e $10,5 \%$ de doutores.

Ao comparar as Tabelas 2 e 3, constata-se que o governo brasileiro, por meio da FINEP, foi o maior incentivador e parceiro da Embrapa no programa de pós-graduação, além, é claro, de ser responsável pelos recursos investidos pela própria Embrapa, no pagamento de salários, quando os pesquisadores 
estavam realizando sua formação. Entretanto, a contribuição do BIRD e BID, tanto em nível nacional quanto internacional, foi muito significativa, bem como a importância da USAID na formação em nível internacional.

Examinou-se quais eram os centros prioritários para a formação do quadro de pesquisadores da Embrapa em sua primeira década de existência. De acordo com o documento "Programa de Pós-Graduação...", anteriormente citado, 28 centros de pós-graduação brasileiros participavam do programa de formação da Embrapa. Já em nível internacional, existiam 89 centros participantes, distribuídos em 18 países.

Murilo Flores discorre a respeito da relação entre o perfil de pesquisadores desejado pela direção da Embrapa e os centros de pós-graduação escolhidos.

A Embrapa na minha época de contratação ainda era dirigida para ser formada em determinadas universidades que era o perfil que a Embrapa queria. A gente tem que lembrar que a Embrapa foi criada no auge do regime militar e ela incorporava muito uma visão de agricultura daquele momento, da grande agricultura, da agricultura moderna e tal com uma visão muito americana, e ela também encarnava o regime autoritário da época, dirigido de cima para baixo. (...). Então isso foi muito bem montado nos anos 70, muito bem pensado por estrategistas - sem aqui emitir juízo de valor a respeito, estou relatando fatos - que estabeleceram com muita competência essa estratégia. E foram arregimentando e treinando em universidades determinadas para as pessoas virem com formação. Por isso que a formação, se você pegar o perfil das pessoas contratadas nos anos 70 , início dos anos 80 , era um perfil muito parecido. Foram pessoas buscadas, com um determinado perfil, treinadas, há muita homogeneidade do pensamento daqueles anos. (...) (Murilo Flores, junho de 2013).

Resumem-se os quadros do documento que tratam dos dados do programa, relativos aos centros de pós-graduação participantes. Na Tabela 4, apresentada a seguir, estão alguns dados relativos à formação no país.Já a Tabela 5 aborda a formação no exterior.

Como mencionado, 28 centros de pós-graduação brasileiros participavam do "programa de pós-graduação da Embrapa". Na Tabela 4 elenca-se informações sobre os dez centros brasileiros que mais formaram profissionais para o programa. Percebe-se, com os dados, que estes dez centros de pós-graduação foram responsáveis, entre os anos de 1974 e 1979, por formar 91,7\% dos mestres ou doutores para o programa. Além disso, observou-se que os mesmos dez centros eram responsáveis, no ano de 1979 , por formar $81,94 \%$ dos profissionais do programa que iriam concluir seus cursos nos próximos anos. Cabe ressaltar que a Universidade Federal de Viçosa (UFV), a Escola Superior de Agricultura Luiz de Queiroz (ESALQ) e Universidade Federal do Rio Grande do Sul (UFRGS), em conjunto, foram responsáveis por 
64,31\% dos cursos concluídos, naqueles cinco anos. Ademais, estas três instituições eram responsáveis, ainda, por formar $56,73 \%$ dos profissionais com os cursos de pós-graduação em andamento. Destaca-se ainda que ESALQ e UFV, de acordo com os dados, eram responsáveis por formar $55 \%$ do total dos pesquisadores (concluídos + em andamento) entre as 10 maiores universidades participantes, o que representava $48,78 \%$ do total nacional.

Tabela 4 - Dez maiores centros formadores do Programa de Pós-Graduação da Embrapa, entre 1974 e 1979, em nível nacional, por número de participantes em relação ao total nacional

\begin{tabular}{l|c|c|c}
\hline Centro de Pós-Graduação & Curso Concluído & Em andamento & Total \\
\hline UFV & 186 & 79 & 265 \\
\hline ESALQ & 138 & 79 & 217 \\
\hline UFRGS & 87 & 40 & 127 \\
\hline UFMG & 47 & 12 & 59 \\
\hline UFPEL & 37 & 14 & 51 \\
\hline UNB & 25 & 16 & 41 \\
\hline UFCE & 20 & 13 & 33 \\
\hline UFSM & 13 & 16 & 29 \\
\hline ESAL & 18 & 8 & 24 \\
\hline UFRRJ & 15 & 9 & $\mathbf{8 7 2}$ \\
\hline Total 10 maiores & $\mathbf{5 8 6}$ & $\mathbf{2 8 6}$ & 988 \\
\hline Total Nacional & 639 & 349 & \\
\hline
\end{tabular}

Fonte: Adaptada do Documento de Departamento de Recursos Humanos/Embrapa (1979).

Em 1979, 484 pesquisadores brasileiros haviam concluído seus cursos, ou estavam realizando seus mestrados ou doutorados no exterior. Como mencionado, participavam do programa 89 centros de pós-graduação, estando eles distribuídos em 18 países. Dos 89 centros participantes, 43 localizavamse nos Estados Unidos. A participação no programa, por país, é apresentada na Tabela 5. Com esta tabela, percebe-se a enorme concentração do "programa de pós-graduação" da Embrapa nos centros de ensino e pesquisa norte-americanos. Dos 239 mestres ou doutores formados no exterior entre 1974 e 1979, 211 haviam realizado seus cursos nos EUA, sendo 88,28\% do total de formados no exterior. Ademais, dos 245 cursos sendo realizados no exterior, no ano de 1979,169 ou 68,97\% eram executados nos EUA.

A comparação do número de profissionais que tinham seus cursos de pós-graduação em andamento no ano de 1979 com o número de profissionais formados entre 1974 e 1979 , revela uma relativa desconcentração, visto 
o aumento na participação de Inglaterra e França. Em todo caso, a centralidade dos Estados Unidos é mantida, sendo seus centros responsáveis pela formação de $2 / 3$ dos pesquisadores.

Tabela 5 - Países participantes do Programa de Pós-Graduação da Embrapa, por número de cursos concluídos e em andamento, em dezembro de 1979.

\begin{tabular}{|c|c|c|c|}
\hline País & Concluído & Em andamento & Tota \\
\hline EUA & 211 & 169 & 380 \\
\hline Inglaterra & 4 & 25 & 29 \\
\hline França & 3 & 20 & 23 \\
\hline Austrália & 2 & 8 & 10 \\
\hline México & 4 & 6 & 10 \\
\hline Cadadá & 5 & 2 & 7 \\
\hline Alemanha & 2 & 4 & 6 \\
\hline Costa Rica & 1 & 2 & 3 \\
\hline Escócia & 3 & 0 & 3 \\
\hline País de Gales & 1 & 2 & 3 \\
\hline Fillipinas & 0 & 2 & 2 \\
\hline Espanha & 0 & 1 & 1 \\
\hline Japão & 1 & 0 & 1 \\
\hline Nova Zelândia & 0 & 1 & 1 \\
\hline Suíça & 1 & 0 & 1 \\
\hline Bélgica & 1 & 0 & 0 \\
\hline Holanda & 0 & 0 & 0 \\
\hline Venezuela & 0 & 0 & 0 \\
\hline Total & 239 & 245 & 484 \\
\hline
\end{tabular}

Fonte: Documento do Departamento de Recursos Humanos da Embrapa (1979).

É importante perceber quais eram os principais centros de formação do "Programa de Pós-graduação" da Embrapa, dentre os 89 mencionados. De acordo com a Tabela 6, entre 1974 e 1979, 67,36\% dos cursos de pósgraduação foram realizados em dez centros formadores, de modo que 53,87\% dos cursos em andamento também se concentravam nesses centros. Percebese ainda que $51,88 \%$ (124) dos cursos concluídos haviam sido realizados nos cinco maiores centros formadores, sendo que 31,33\% (78) dos cursos em andamento estavam sendo realizados nestes mesmos centros. A tabela 4 também evidencia a entrada de Montpellier, após 1979, entre os centros de formação importantes, pois, nesse ano, tal centro configurava-se como o segundo maior formador do programa de pós-graduação em andamento, provavelmente em função do acordo de $1975^{17}$. 
Tabela 6 - Dez maiores centros formadores do Programa de Pós-Graduação da Embrapa, entre 1974 e 1979, em nível internacional, por número de participantes em relação ao total internacional

\begin{tabular}{l|c|c|c|c}
\hline Centro de Pós-Graduação & Concluído & Em andamento & Total & $\begin{array}{c}\text { \% do total } \\
\text { internacional }\end{array}$ \\
\hline Florida - EUA & 29 & 26 & 55 & 11,36 \\
\hline Purdue - EUA & 25 & 15 & 40 & 8,28 \\
\hline Wisconsin - EUA & 23 & 14 & 37 & 7,64 \\
\hline Mississippi - EUA & 26 & 10 & 36 & 7,43 \\
\hline California Davis - EUA & 21 & 13 & 34 & 7,02 \\
\hline North Carolina - EUA & 12 & 14 & 26 & 5,37 \\
\hline lowa - EUA & 13 & 9 & 22 & 4,75 \\
\hline Montpellier - França & 1 & 18 & 19 & 3,92 \\
\hline Michigan - EUA & 6 & 9 & 15 & 3,09 \\
\hline Nebraska - EUA & 161 & 132 & 293 & 60,53 \\
\hline Total 10 maiores & 239 & 245 & 484 & 100 \\
\hline Total Internacional & & 4 & 9 & 1,85 \\
\hline
\end{tabular}

Fonte: Documento do Departamento de Recursos Humanos da Embrapa (1979)

De acordo com o documento "Programa de Pós-Graduação da Embrapa no periodo de 1974-1979", a empresa havia formado no exterior, entre 1974 e 1979, 150 mestres e 43 doutores. Da mesma forma, observou-se que dos 245 profissionais em formação no exterior, no ano de 1979, 52 eram funcionários da Embrapa que faziam mestrado, e 95 eram funcionários que faziam doutorado.

Ao comparar o documento supracitado com a Tabela 6 evidencia-se que os dez maiores centros formadores do exterior foram responsáveis por formar cerca de 120 mestres e 41 doutores para a Embrapa e demais instituiçóes participantes do programa. Além disso, em 1979, o "programa” mantinha 54 mestrandos e 78 doutorandos nestes centros. Ao considerar os cinco maiores centros formadores, percebe-se que eles concentraram, entre 1974 e 1979, a formação de 92 mestres e 32 doutores para o "Programa de Pós-Graduação". Além disso, em 1979, existiam nestes cinco centros 32 mestrandos e 45 doutorandos.

Ao analisar tal documento busca-se compreender onde eram realizados os mestrados e os doutorados pelo "programa de pós-graduação" da Embrapa. Reorganiza-se os dados, conforme a Tabela 7 e então percebe-se que $77,72 \%$ dos mestres, formados entre 1974 e 1979 , realizaram seus cursos no Brasil. Por outro lado, $77,21 \%$ dos doutores formados no período realizaram seus cursos no exterior. Além disso, evidencia-se que 76,06\% dos mestres 
em formação realizavam seus cursos no Brasil, no ano de 1979. Por outro lado, $83,73 \%$ dos doutorandos faziam seus cursos no exterior, naquele ano (Tabela 7).

Tabela 7 - Número de cursos de pós graduação, por grau (MSc ou PhD) e por local (país ou exterior), no ano de 1979.

\begin{tabular}{|l|c|r|r|r|}
\cline { 2 - 5 } \multicolumn{1}{c|}{} & \multicolumn{2}{c|}{ Concluíram } & \multicolumn{2}{c|}{ Em andamento } \\
\cline { 2 - 5 } \multicolumn{1}{c|}{} & MSC & PhD & MSC & PhD \\
\hline País & 621 & 18 & 321 & 28 \\
\hline Exterior & 178 & 61 & 101 & 144 \\
\hline Total & 799 & 79 & 422 & 172 \\
\hline
\end{tabular}

Fonte: Documento do Departamento de Recursos Humanos da Embrapa (1979).

Ao relacionar as Tabelas 5, 6, e 7 constata-se: 1) a formação era pensada de tal maneira que os profissionais fizessem seus mestrados no Brasil e seu doutorado no exterior; 2) quando afirma-se que o mestrado era realizado no Brasil, deve-se ter em mente que cerca de $2 / 3$ dos profissionais realizavam seus cursos de mestrado em três instituiçóes, UFV, ESALQ e UFRGS, sendo a maior parte destes formados na UFV e ESALQ (cerca de 50\% do total); 3) ao afirmar que o doutorado era realizado no exterior, deve-se ser mais específicos, sendo que, entre 1974 e 1979, nove em cada dez profissionais que foram para o exterior fizeram seus cursos nos Estados Unidos, e no ano de 1979 oito em cada dez doutorandos realizavam seus cursos nos EUA; 4) entre 1974 e 1979, dois em cada três profissionais realizaram seus cursos em um dos nove centros norte-americanos, descritos na Tabela 6. Tal concentração nestes centros diminui um pouco em 1979, sendo eles responsáveis por $46,53 \%$ dos profissionais em formação no exterior.

Desta maneira conclui-se que existia uma espécie de trajeto: primeiramente os profissionais faziam mestrado no Brasil, normalmente na UFV, ESALQ ou UFRGS e, posteriormente, faziam doutorado nas universidades norte-americanas, com grande preponderância daquelas citadas na Tabela 6 . Com relação a estas três universidades brasileiras responsáveis por parte $\mathrm{da}$ qualificação acadêmica do quadro profissional da Embrapa, destaca-se:

Em 1963, uma intensa colaboração entre quatro universidades brasileiras e quatro americanas foi iniciada com apoio financeiro da USAID. (...) Um dos objetivos do programa era melhorar a qualidade do quadro de funcionários das universidades brasileiras (o programa normalmente incluía cursos de pós-graduação no exterior, principalmente nos Estados Unidos); um outro foi desenvolver programas de pós-graduação em várias universidades brasileiras. As quarto universidades brasileiras e suas contrapartes americanas foram a Universidade 
Federal do Ceará com a Universidade do Arizona, a Universidade Federal de Viçosa com a Universidade de Purdue, a Escola Superior de Agricultura "Luiz de Queiroz" (ESALQ) da Universidade de São Paulo com Universidade do Estado de Ohio e a Universidade Federal do Rio Grande do Sul com a Universidade de Wisconsin (BEINTEMA et. al., 2001, p. 17 apud SANDERS et al. 1989).

Evidencia-se a imensa influência dos centros de pesquisa norteamericanos voltados para a agropecuária sobre a reestruturação da pesquisa agropecuária brasileira, ocorrida na década de 1970. Mesmo no período da formação de mestrado os pesquisadores eram influenciados pelo ensino norte-americano, pois a maior parte deles realizava seus cursos na UFV, ESALQ e UFRGS, universidades estas, que de acordo com Beintema (2001), desenvolviam seus cursos de pós-graduação por meio de acordo com a Universidade de Purdue, Universidade do Estado de Ohio e Universidade de Wisconsin, respectivamente.

\section{CONSIDERAÇÕES FINAIS}

Analisou-se alguns dos aspectos fundamentais para a compreensão daquilo que se tornou a espinha dorsal da constituição do quadro profissional da Embrapa. Com este trabalho evidenciou-se a necessidade, por parte dos idealizadores e dirigentes da Embrapa, de modificar, completamente, a formação acadêmica dos pesquisadores que por ela viriam a ser contratados. Aos profissionais da Embrapa não bastava a formação recebida no Brasil, pois precisavam compreender a ciência voltada para uma agricultura industrializada. Desta maneira, deveriam se qualificar nos centros promotores daquele modelo de agricultura. Mesmo aqueles que faziam pós-graduação no Brasil, majoritariamente, realizavam seus cursos em universidades profundamente influenciadas pelo modelo de ciência para a agropecuária provindo dos EUA.

Nesse sentido, a instituição, para atingir os objetivos de seus criadores, não recrutou seu quadro, simplesmente. De forma planejada, os enviou para centros de pesquisa específicos. Tal política de seleção e formação deveria garantir que seus profissionais tivessem valores semelhantes, que falassem a mesma linguagem, que entendessem a agricultura e a realidade brasileira da mesma maneira e, assim, que concordassem em atuar no mesmo sentido.

$\mathrm{Na}$ burocratização do think tank nascente, seus dirigentes não visavam apenas o domínio das ferramentas de trabalho dos pesquisadores, para assim decidir sobre os rumos da instituição. Visavam e decidiram sobre os conhecimentos que seu quadro deveria ter, sobre os princípios científicos básicos 
que deveriam partilhar. Desta maneira contribuiriam decisivamente na definição dos rumos a serem trilhados pela empresa. A vigência da ordem, para além do sentimento de dever característico de anos de rotina, deveria ser obtida por uma formação acadêmica relativamente homogênea.

Como destacado nos relatos dos interlocutores, o poder de agência dos profissionais contratados na escolha de sua área de especialização, bem como do centro de pós-graduação do qual fariam parte, era aparentemente muito baixo ou nulo. Deste modo, conclui-se que um critério de fechamento da empresa era este, e quem não aceitava realizar pós-graduação na área ou local eleito pelo Departamento de Recursos Humanos não era admitido.

Com as regras formais da organização definidas e com um maior controle sobre as convençôes, estabelecido por meio da seleção e da formação acadêmica de seu quadro, seria bastante difícil que a empresa saísse dos rumos planejados por seus idealizadores.

\footnotetext{
Notas

1 Vide Beintemaet al (2001), EMBRAPA (2010; 2013), Mengel (2015).

2 Para este autor uma ação social consiste naquela que "orienta-se pelo comportamento de outros, seja este passado, presente ou esperado como futuro (...). Os "outros" podem ser indivíduos e conhecidos ou uma multiplicidade indeterminada de pessoas completamente desconhecidas (...)"(WEBER, 2009, p. 1314).

${ }^{3}$ Instituição é "uma associação cuja ordem estatuída se impõe, com (relativa) eficácia, a toda ação com determinadas características que tenha lugar dentro de determinado âmbito de vigência".(...) Uma instituição é, sobretudo, o próprio Estado junto com todas suas associações heterocéfalas (...). As ordens de uma "instituição" pretendem vigência para toda pessoa a qual se aplicam determinadas características (nascimento, domicílio, utilização de determinados serviços), sendo indiferente se pessoalmente se associou ou não e, menos ainda, se participou ou não na elaboração dos estatutos. São, portanto, ordens impostas no sentido específico da palavra (WEBER, 2009, p. 32-33).

${ }^{4}$ Uma análise sobre a configuração organizacional do DNPEA, bem como das modificações ocorridas em sua estrutura é encontrada em Rodrigues (1987) e Mendonça (2012).

${ }^{5}$ Ministério da Educação e Cultura.

'Levon Yeganiantz nasceu na antiga União Soviética, graduou-se na Universidade Americana de Beirute, fez mestrado em Desenvolvimento Agrícola em Dakota do Sul, nos EUA, e Doutorado pela Universidade de Myraland, EUA. Trabalha na Embrapa desde 1975. Entrou na Embrapa como perito da Organização dos Estados Americanos, da qual era funcionário, e após dez anos foi efetivado no quadro de funcionários da empresa. Desde 1975, foi assessor da presidência da empresa em quase todos os mandatos, acumulando larga experiência junto com a sua direção.

${ }^{7}$ Think Tanks são instituições de pesquisa, análise e engajamento em políticas públicas. Além de gerarem pesquisas e análises politicamente orientadas, buscam sensibilizar a sociedade e os tomadores de decisão quanto a temas de seu interesse. São, portanto, mais do que "Think" Tanks; caracterizamse na prática como "Think-and-Do" Tanks. (ISAPE, 2012, p. 1). A efetividade de um Think Tanks deve ser medida de acordo com o impacto que possui na esfera da sociedade e na esfera do governo/Estado. (...) Os ThinkTanks traduzem pesquisas básicas e aplicadas em linguagem compreensível, confável e acessível. Assim, sua capacidade de impactar ambas as esferas (sociedade e governo/Estado) dependerá de suas competências técnico-analíticas, seu papel na comunidade epistêmica, seu grau e tipo de financiamento e a funcionalidade de seus produtos (inteligência política) (ISAPE, 2012, p. 4).

${ }^{8}$ Instituto de Pesquisa e Experimentação Agronômica do Sul.
} 
${ }_{9}^{9}$ Alberto Miele é Engenheiro Agrônomo, desde 1965, Mestre pela University of California at Davis, 1977 e Doutor em Viticultura e Enologia pela Université de Bordeaux II, 1986. Pesquisador do DNPEA desde 1972 e pesquisador da Embrapa desde 1973, atuando no Centro Nacional de Uva e Vinho até os dias atuais.

${ }^{10}$ Elsio Antônio Pereira Figueiredo é Zootecnista, formado pela UFSM no ano de 1975, fez mestrado em Zootecnia pela UFV (1976-1978) e Doutorado em Animal Breeding pela Texas A\&M (1983-1986). Foi contratado pela Embrapa em 1975. Atuou como pesquisador na Embrapa Caprinos entre 1978 e 1990. Atua na Embrapa Suínos e Aves desde 1990 até a presente entrevista. Desempenhou as funções de Chefe de Pesquisa e Desenvolvimento na Embrapa Caprinos (1986 e 1988); Chefe Geral da Embrapa Caprinos (1988-1990); Chefe de Pesquisa e Desenvolvimento da Embrapa Suínos e Aves e Chefe Geral da Embrapa Suínos e Aves (2004-2009).

${ }^{11}$ José Carlos Souza Silva é Biólogo, formado pela UNICAMP no ano de 1976, fez mestrado em Fisiologia Vegetal pela UNICAMP (1981-1983) e doutorado em Fisiologia Vegetal pela Universidade de Edimburgo (1989-1993). Atuou como pesquisador da Embrapa Cerrados desde 1977 até a presente entrevista. Desempenhou as funções de Gestor de recursos humanos, socioeconômicos e informática em 1988; e Secretário Executivo da Secretaria de Recursos Naturais da Embrapa (1998-2002).

${ }^{12}$ Dirceu João Duarte Talamini é Engenheiro Agrônomo, formado pela UFSM no ano de 1973, fez mestrado em Economia pela UFRGS (1975-1977) e doutorado em Economia Rural pela Universityof Oxford (19841989). Atuou como pesquisador da Embrapa Milho e Sorgo entre 1974 e 1975. Atua na Embrapa Suínos e Aves desde 1977 até a presente entrevista. Desempenhou as funções de Coordenador de Sistemas e Análises Econômicas do Centro Nacional de Pesquisa de Suínos e Aves (1978); Chefe Adjunto Técnico do Centro Nacional de Pesquisa de Suínos e Aves (1978 - 1984); Coordenador do Programa de Cooperação Técnica Embrapa - INRA (1981 - 1984); Chefe Geral do Centro Nacional de Pesquisa de Suínos e Aves (1996 - 2000) (2001 - 2004) (2009 até presente entrevista).

${ }^{13}$ Agência, esta é a capacidade de interferir em eventos, não necessariamente de modo intencional. Agir, mais do que pretender algo, é ser significativo na sua ocorrência, na medida em que a "ação depende da capacidade do indivíduo de 'fazer uma diferença' em um estado pré-existente de coisas ou curso de eventos" (GIDDENS, 1984, p. 14).

${ }^{14}$ Uma das características definidoras da Embrapa é o planejamento detalhado de sua atuação. Esta característica a diferencia completamente da instituição que a antecedeu. Tal planejamento torna-se parte da ordem vigente da empresa e é a partir dele que são estudadas e operadas todas as táticas por ela desenvolvidas. Desde a atuação no ambiente parlamentar, passando pela formação, até a atuação de comunicação, tudo faz parte da estratégia de planejamento estabelecida, e não somente a programação e execução da pesquisa. O planejamento modifica a estrutura de pesquisa, até então utilizada pela antiga instituição do Ministério da Agricultura, departamentalizada, e passa a utilizar uma estrutura baseada em sistemas de produção. Nesta modificação, economistas e sociólogos passaram a ocupar papel central na área do planejamento, que passa a ter uma lógica econômica e não mais agronômica, como era usual. Mais informações, ver Mengel (2015).

${ }^{15}$ Fernando Campos é Medico Veterinário, formado pela Universidade Federal de Minas Gerais, no ano de 1968. Fez mestrado na mesma universidade, na área de produção animal, concluindo-o em 1974. Realizou doutorado na área de fisiologia da reprodução, na Univesidade da Flórida, concluíndo em 1982. Iniciou sua vida profissional no Instituto de Pesquisa da Amazonia Ocidental, subordinado ao Ministério da Agricultura. Entrou na Embrapa em 1974, atuando, inicialmente, no Centro Nacional de Pecuária de Corte. Posteriormente, passou a atuar no Departamento Técnico Científico, onde desenvolveu toda sua trajetória profissional, tal departamento passou a denominar-se Departamento de Pesquisa e Desenvolvimento.

${ }^{16}$ O acordo entrea United States Agency for International Development (USAID) e Ministério da Agricultura, firmado em 1971, financiou a formação, entre 1974 e 1979, de 35,5\% dos mestres e 10,5\% dos doutores que realizaram seus cursos no exterior pelo Programa de Pós Graduação da Embrapa, o que corresponde a 104 mestres e 23 doutores. Seus objetivos eram: a. Promover o treinamento de pesquisadores brasileiros em atividades, e, de recém-formados pelas Faculdades de Agronomia, designando-os para atuar em Projetos Nacionais de Pesquisa sob a orientação de cientistas brasileiros e estrangeiros de alto nível, apoiados por equipes de cientistas coadjuvantes e bolsistas. b. Criar oportunidades de estudo avançado para cientistas com grande potencial. c. Treinar grupos de pesquisadores brasileiros em diferentes disciplinas, a serem distribuídos em locais estratégicos do país, a fim de trabalhar nos Projetos de Pesquisa ligados aos problemas da produção de arroz, milho e sorgo, soja, feijão e bovinos (EMBRAPA, 1975, s/p). Tal programa, iniciado anteriormente à criação da Embrapa, considerava os seguintes procedimentos para a seleção dos participantes: A indicação dos candidatos para toda e qualquer modalidade de treinamento adotado, será feita pela entidade diretamente interessada à Superintendência do Programa, através dos diretores dos Projetos Nacionais de Pesquisa. A equipe norte-americana do Programa de Empréstimo deverá dar assessoramento necessário para: a. determinar a quantidade de técnicos a serem treinados. b. 
indicar as instituições mais recomendadas para treinamento no exterior. c. planejar e participar dos programas de treinamento. Os objetivos do Programa de Empréstimo não podem ser alcançados de modo nenhum, se os técnicos norte-americanos dos Projetos Nacionais de Pesquisa, não tomarem parte da seleção dos candidatos, indicação da área de especialização, locais apropriados para o treinamento e auxílio na preparação e defesa de tese (EMBRAPA, 1975, s/p). Mais informações sobre o programa, ver Mengel (2015).

${ }^{17}$ No ano de 1975 a Embrapa celebrou acordo de cooperação técnica com o governo francês. Os objetivos do programa eram:"Assessorar a EMBRAPA no planejamento e implantar programas adequados de pesquisa dos seguintes produtos nas respectivas regiões de importância econômica: Seringueira no Norte, Nordeste e Sudeste; Vitivinicultura no Nordeste, Sudeste e Sul; Dendezeiro e Coqueiro no Norte e Nordeste; Algodão no Nordeste e Sudeste. Os programas de pesquisa visam, a curto prazo, ao atendimento da demanda dos produtos no país e no mercado internacional. A longo prazo visa ao desenvolvimento de tecnologias e sistemas de produção eficientes para as condições regionais" (EMBRAPA, 1975a, p.7).

\section{Referências Bibliográficas}

ALVES, E. As unidades de difusão de tecnologia da Embrapa. Brasília, 1975. In: Coletânea de Trabalhos sobre a Embrapa. Brasília, 1977.

ALVES, E. R. de A.; PASTORE, J.; PASTORE, A. C. O papel da tecnologia na expansão agrícola. In: Coletânea de Trabalhos sobre a Embrapa. Brasília, 1977.

BEINTEMA, N. M.; AVILA, A. F. D.; PARDEY P. G. P\&D Agropecuário: Política, Investimentos e Desenvolvimento Institucional. Washington, D.C.: IFPRI, Embrapa \& Fontagro, agosto 2001. BOURDIEU, P. Os Usos Sociais da Ciência - Por uma Sociologia Clínica do Campo Científico. Conferência e debate organizados pelo grupo SciencesandQuestions. São Paulo. Editora UNESP, 1997.

EMBRAPA. Coordenação de

Desenvolvimento de Pessoal. Informações sobre o projeto de pós-graduação (Versão Preliminar). Departamento de Recursos Humanos. Embrapa, Brasília, 1975. O futuro da agricultura está sendo construído agora. Revista Agroanalysis, v. 33, n. 04, Fundação Getúlio Vargas, São Paulo, 2013.

Secretaria de Gestão Estratégica. Balanço Social 2010. Embrapa, Brasília, 2011. INSTITUTO Sul-Americano de Política e Estratégia - ISAPE. Think tanks: Conceito, Casos e Oportunidades no Brasil. In: ISAPE Debate, n. 2, out. 2012.
MENDONÇA, Sônia Regina de. Entidades patronais agroindustriais e a política de pesquisa agropecuária no Brasil (19632003). Raízes, v. 32, n. 2. Campinas, 2012. Disponível em: https://bit.ly/3d8kMrp. Acesso em: 15 nov. 2019.

MENGEL, A. A. Modernização da agricultura e pesquisa no Brasil: a Empresa Brasileira de Pesquisa Agropecuária Embrapa. Tese (doutorado) - Universidade Federal Rural do Rio de Janeiro, Instituto de Ciências Humanas e Sociais, Seropédica, 2015.

RODRIGUES, C. M. A pesquisa

Agropecuária no período do Pós-Guerra, Cadernos de Difusão de Tecnologia, v. 4. n. 3. Brasília, 1987.

SHRADER, O. L. \& CABRAL, J. I. Sugestões para a Formulação de um Sistema Nacional de Pesquisa Agropecuária, 1972. In: EMBRAPA. Sugestões para a Formulação de um Sistema Nacional de Pesquisa Agropecuária. Edição Especial do documento original de julho de 1972. Brasília, 2006.

SOUZA, I. S. F. \& TRIGUEIRO, M. G. S. Organização da Pesquisa Agropecuária Brasileira: O caso da EMBRAPA. Caderno de Difusão Tecnológica, Brasília, v. 6,n. 2/3, p. 277-337, maio/dez, 1989.

WEBER, M. Economia e Sociedade Volume 1. Brasília. Editora UnB. 2009. 